\title{
Protective Effect of QiOne® 2 Pro on Cultured Intestinal Epithelial Cells after Mobile Phone Radiation
}

\author{
Peter C Dartsch* \\ Dartsch Scientific GmbH, Institute for Cell Biological Test Systems, Auf der Voßhardt 25, D-49419 Wagenfeld, Germany \\ *Corresponding author: Peter C Dartsch, Dartsch Scientific GmbH, Institute for Cell Biological Test Systems, Auf der Voßhardt \\ 25, D-49419 Wagenfeld, Germany, E-mail: pc.dartsch@dartsch-scientific.com
}

\section{ABSTRACT}

QiOne ${ }^{\circledR} 2$ Pro is a specific device which creates a static field that stimulates water molecules to undergo a transition into the coherent state. Since our body consists of about 70 to $85 \%$ of water (depending on age), this coherent state of the water molecules might increase the cellular resistance against exogenous reliabilities such as electromagnetic fields. In this study, the protective effect of QiOne ${ }^{\circledR} 2$ Pro against mobile phone radiation was examined by using the cultured intestinal epithelial cells. Unprotected cells and untreated control cells served as point of reference. The cell regeneration process as well as the integrity of the intestinal epithelial barrier was investigated by measuring the transepithelial electrical resistance.

Mobile phone radiation caused a reduced cell regenerative activity by approximately $60 \%$, whereas the values were about $15 \%$ for QiOne ${ }^{\circledR} 2$ Pro protected cells and untreated controls, respectively. Moreover, mobile phone radiation caused a rupture on the epithelial barrier in unprotected cells by cell death caused due to the oxidative stress with a complete loss of morphological integrity on the barrier. In contrast, untreated controls and QiOne ${ }^{\circledR} 2$ Pro protected cells did not show any morphological change on the cell layers with an epithelial barrier of a 10-fold higher transepithelial electrical resistance than the unprotected cells.

Overall the results clearly demonstrate the sensitivity of intestinal barrier against oxidative stress generated by mobile phone radiation. In addition, the results also show that the QiOne ${ }^{\circledR} 2$ Pro device is able to reduce unwanted cellular effects of mobile phone radiation.

\section{ABBREVIATIONS}

TEER: Transepithelial Electrical Resistance

\section{INTRODUCTION}

The intestinal epithelium with single cell layer thickness has two essential tasks. The first one is to create a physical barrier between the contents of the intestinal lumen and the rest of our body. The second one is to ensure an efficient absorption of essential nutrients from the gut lumen and to produce mucus, anti-microbial peptides and cytokines with both protective and immune-regulatory properties. Thus, a reduced barrier function may have far reaching consequences, not only for intestine, but also for systemic health [1]. This barrier function can be destroyed by oxidative stress [2] as generated by mobile phone radiation.

Despite the ubiquity of electromagnetic field emitters, the influence on living organisms and cells has become the subject of numerous research studies with contradictory results [3-6]. 


\section{Research Article}

However, it has been demonstrated that oxidative stress plays a key role in the events causing cell death [7-11]. Although the gastrointestinal tract does not play a key role in the mobile phone radiation studies, there are some articles dealing with the effect of electromagnetic radiation on the intestine. For example, in an experimental animal study Sieron et al. [12] demonstrated that electromagnetic radiations modified the redox balance in the gastrointestinal tract of rats. This might enhance the sensitivity against intestinal oxidative stress by injury or disease with all its unwanted health consequences.

According to the manufacturer, Qi Blanco UG (haftungsbeschränkt) from Germany, the QiOne ${ }^{\circledR} 2$ Pro device contains a grid chip which forms a static field that stimulates water molecules to undergo a transition into the coherent state. Since our body consists of about $70-85 \%$ of water (depending on age), the coherent state of the water molecules positively influence the cells of our whole body. Moreover, QiOne ${ }^{\circledR}$ 2 Pro is stated to neutralize the unwanted effects of mobile phone radiation.

In this present in vitro study, current bioassays were used to investigate whether the use of QiOne ${ }^{\circledR} 2$ Pro might result in a protective effect on cultured intestinal epithelial cells against mobile phone radiation and the arising oxidative stress.

\section{MATERIAL AND METHODS}

\section{QiOne® 2 Pro device}

QiOne ${ }^{\circledR} 2$ Pro was provided by Qi Blanco UG (haftungsbeschränkt), D-97711 Maßbach, Germany, for the duration of the experiments. The device is a second generation grid chip of a specifically developed gold alloy with eightfold strength which creates a static field that stimulates water molecules to enter a coherent state in your body.

\section{Mobile phone}

A current and commercially available mobile phone from a leading brand manufacturer with a SAR value of $0.76 \mathrm{~W} / \mathrm{kg}$ was used. No distinction was made between thermal and nonthermal radiation, because both are also present in reality when making a call and have an effect on the human body.

\section{Cultivation of intestinal cells}

The investigations presented here were conducted with IPEC-J2 cells (ACC-701; Leibniz Institut, DSMZ, Braunschweig, Germany). The cells were grown in Dulbecco's Modification of Eagles Medium (DMEM; $1.0 \mathrm{~g} / \mathrm{L}$ glucose) with $10 \%$ growth mixture and $0.5 \%$ gentamycin and cultivated in an incubator at $37^{\circ} \mathrm{C}$ in an atmosphere of $5 \% \mathrm{CO}_{2}$ and $95 \%$ air at nearly $100 \%$ humidity. The cells were cultivated as mass cultures and were regularly subcultured twice a week with fresh culture medium. For the experiments, cells were taken from $80-90 \%$ confluent mass cultures.

\section{Cell regeneration after mobile phone radiation}

Cells were seeded at a density of 100,000 cells $/ \mathrm{ml}$ into the four individual compartments of a silicone 4 well-culture insert made (ibidi, Gräfelfing, Germany). The single compartments of the inserts are separated by a $500 \mu \mathrm{m}$ thick silicone bar with an outer silicone frame of $700 \mu \mathrm{m}$. Due to the special adhesion area, an insert adheres firmly to the bottom of a culture dish and forms a distinct cell-free area (artificial wound) in which the cells can colonize by migration and proliferation. Upon reaching confluency within 48 hours after cell seeding, the cells were exposed to the radiation of an actively transmitting mobile phone \& WLAN with and without QiOne ${ }^{\circledR} 2$ Pro. The cell culture dish was placed on the mobile phone display (direction of radiation towards the user) in a mini-incubator for 4 hours at $37^{\circ} \mathrm{C}$ without gassing (Figure 1). To avoid any $\mathrm{pH}$ changes during exposure at normal air conditions, the routine culture medium was replaced by Leibowitz L-15 medium with $1 \%$ growth mixture and $0.5 \%$ gentamycin. Cells which were cultured in the same way, but without mobile phone radiation, served as corresponding controls. After 4 hours of radiation, cells were incubated for another 8 hours in the same culture medium. Finally, cells were fixed with methanol, stained with Giemsa's azur eosin methylene blue solution (Merck, Darmstadt, Germany), air-dried and examined by micrographs and a specialized software with artificial intelligence from KML Vision, Graz, Austria (IKOSA AI software).

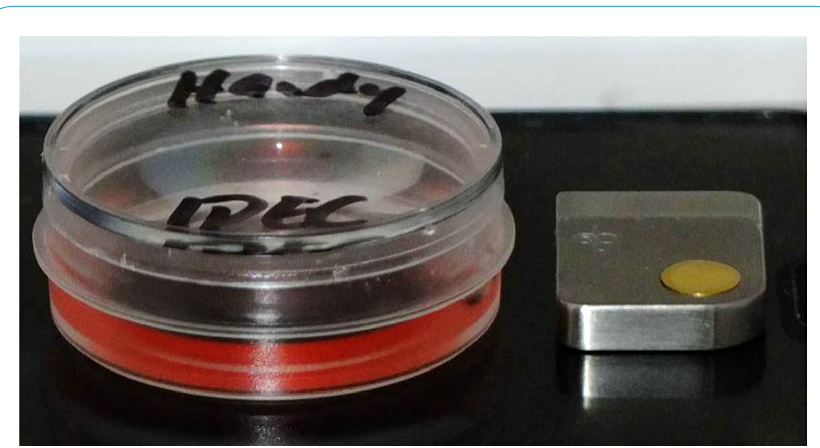

Figure 1: Arrangement of cell culture dish which was placed on the mobile phone display (direction of radiation towards the user) together with a QiOne ${ }^{\circledR} 2$ Pro device on the right side. 
Transepithelial electrical resistance (TEER) after mobile phone radiation

IPEC-J2 cells were grown for 5 days on the surface of a 0.4 $\mu \mathrm{m}$ porous membrane (transwell plate, Corning, SigmaAldrich, Deisenhofen, Germany) which yields two seperated compartments within the cell culture dish. As a matter of fact, the cells covering the surface of the membrane represent a physical barrier against the lower compartment. TEER was measured by placing one electrode in the culture medium in the upper compartment and by placing one electrode in the culture medium in the lower compartment. Electrical resistance was directly measured by a portable voltmeter (Millicell ERS-2 Voltmeter, Millipore/Merck, Darmstadt, Germany) as described in detail elsewhere $[1,13,14]$.
Epithelial cell layers were taken for the experiments at an electrical resistance of at least 2,000 $\Omega / \mathrm{cm}^{2}$ representing an intact physical barrier with very good integrity and were exposed to the actively transmitting mobile phone mobile phone \& WLAN with and without QiOne ${ }^{\circledR} 2$ for 4 hours at $37^{\circ} \mathrm{C}$ as already described. After another 24 hours of cultivation, TEER was measured again and data were compared to each other. Three independent experiments were conducted. As a reference, TEER of the porous membranes without any cell barrier was measured to be 150 to $180 \Omega / \mathrm{cm}^{2}$.

\section{RESULTS}

\section{Cell regeneration}

As seen in Figures 2 and 3, mobile phone radiation caused a reduction in cell regenerative activity by leaving a cell-free area
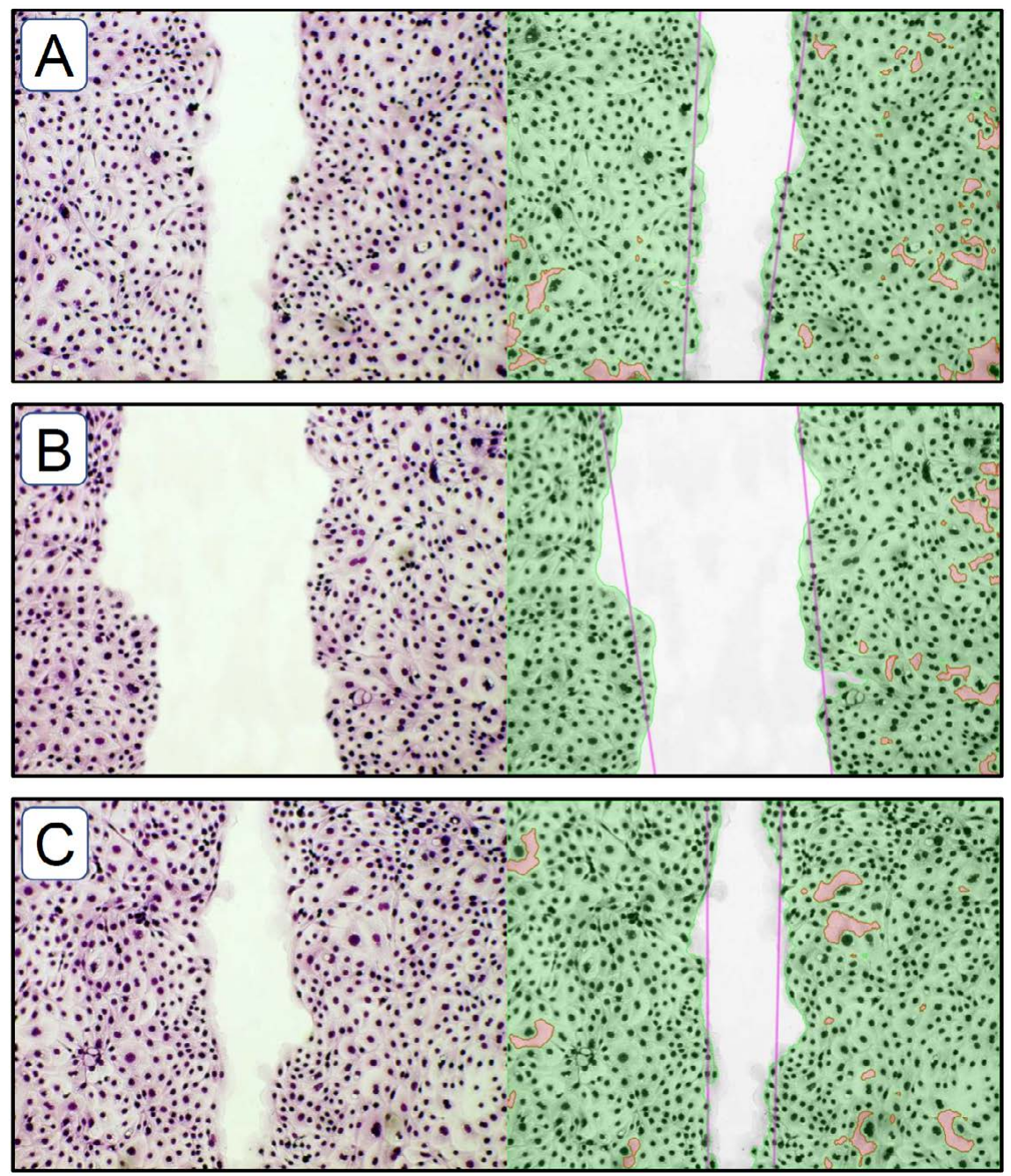

Figure 2: Original micrographs (left part) as well as the evaluation by IKOSA AI software (right part) with marked calculated frontlines of the IPEC-J2 cells closing the cell-free area. (A) Untreated control at the same culture conditions as below, but without any exposure to mobile phone radiation. (B) Unprotected cells after 4 hours of mobile phone radiation with subsequent cultivation for 8 hours. (C) QiOne ${ }^{\circledR} 2$ Pro protected cells after 4 hours of mobile phone radiation with subsequent cultivation for 8 hours. Note the largely decreased colonization of the cell-free area in (B). Untreated control and QiOne ${ }^{\circledR} 2$ Pro protected cells show a similar colonization pattern. 


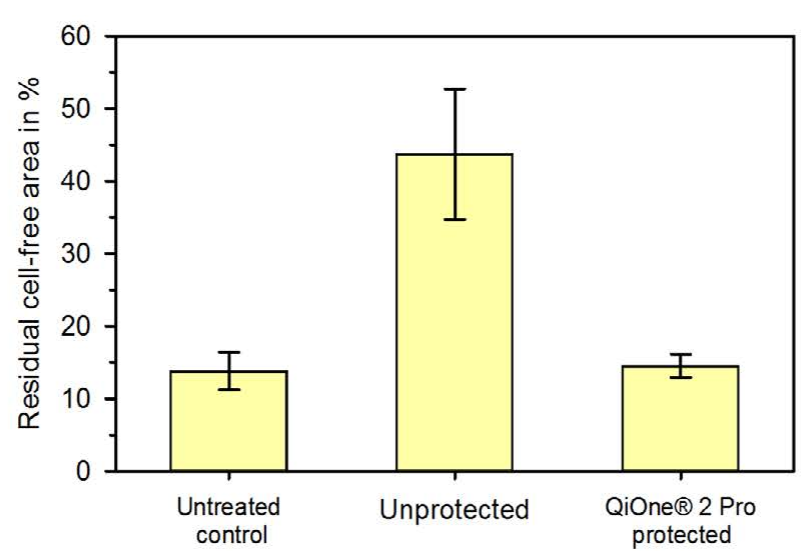

Figure 3: Presentation of the results on cell regeneration after mobile phone exposure with and without QiOne ${ }^{\circledR}$ 2 Pro for 4 hours and subsequent cultivation for 8 hours. Note that the residual cell-free areas of untreated control and QiOne ${ }^{\circledR} 2$ Pro protected cells do not differ from each other, whereas unprotected cells have a significant higher cell-free area due to a markedly reduced cell activity and even cell death. Data represent mean value \pm standard deviation of four independent experiments. which was $43.7 \pm 9.0 \%$ (mean value \pm standard deviation; $n=4$ ) in comparison to the total colonized cell area. In contrast, the residual cell-free area was only $13.8 \pm 2.6 \%$ for the untreated control and $14.5 \pm 1.6 \%$ for the QiOne ${ }^{\circledR} 2$ Pro protected cells (both mean values \pm standard deviations; $n=4$ ). The difference between the unprotected cells and QiOne ${ }^{\circledR} 2$ Pro protected cells was statistically significant ( $\mathrm{p} \leq 0,01$; two-tailed WilcoxonMann-Whitney test) demonstrating the effectiveness of the device against mobile phone radiation. Moreover, there was no statistically relevant difference between the QiOne ${ }^{\circledR} 2$ Pro protected cells and the cells which were not exposed to mobile phone radiation at all.

\section{Transepithelial electrical resistance (TEER)}

As seen in Figure 4, mobile phone radiation caused a rupture on the epithelial barrier by causing cell death due to oxidative stress. In contrast, untreated controls and QiOne ${ }^{\circledR} 2$ Pro protected cells did not show such massive morphological changes of the cell layers. This situation is reflected by the TEER values measured. For the unprotected cells a TEER of $152 \pm 16 \Omega / \mathrm{cm}^{2}$ was measured demonstrating the complete
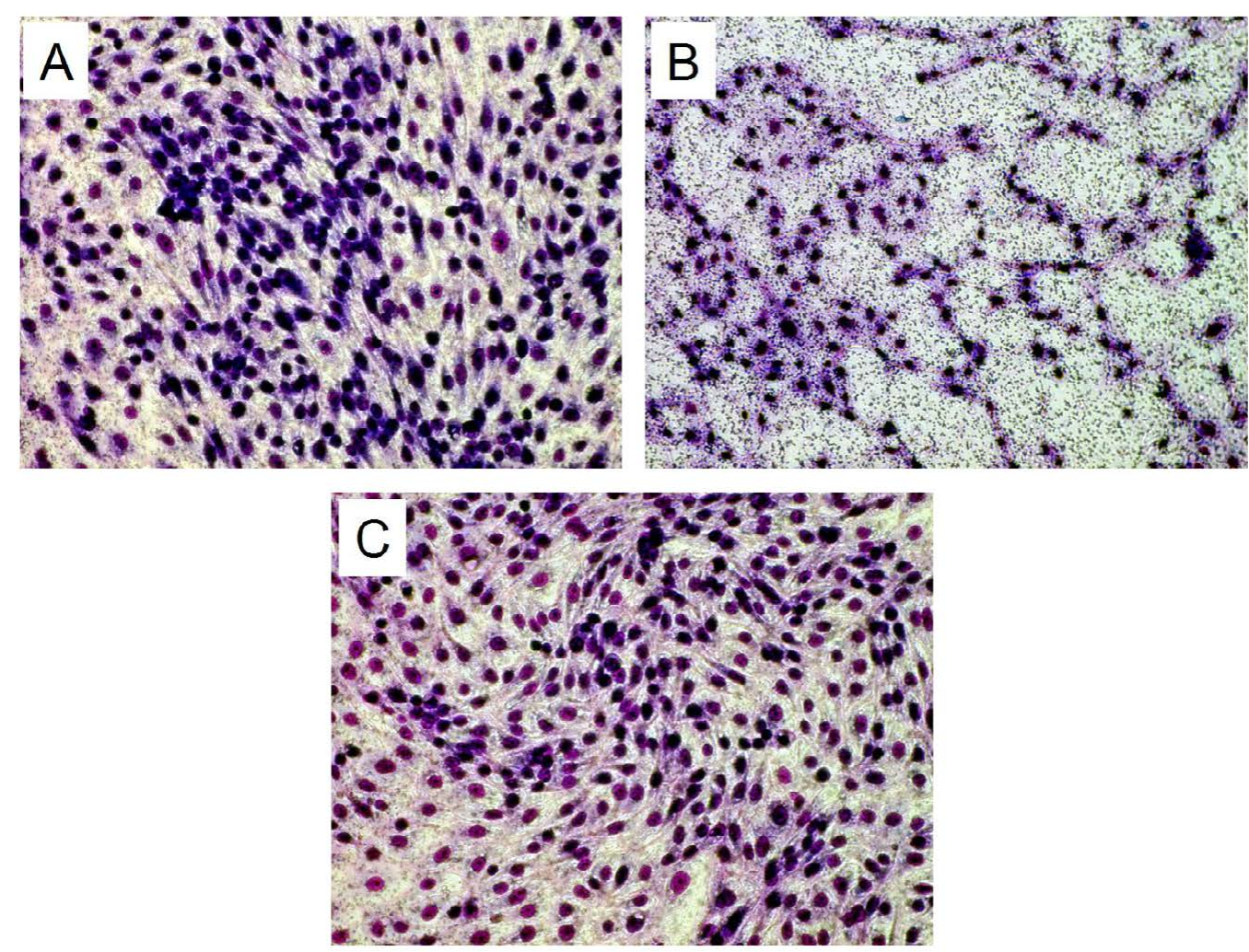

Figure 4: Original micrographs of IPEC-J2 cells establishing a physical barrier on the porous membranes of transwells after 4 hours of mobile phone radiation with subsequent cultivation for 24 hours. (A) Untreated control. (B) Unprotected cells. (C) QiOne ${ }^{\circledR} 2$ Pro protected cells. The small dark points are the $0.4 \mu \mathrm{m}$ pores in the membrane and the purple stained structures are the cell nuclei. The cytoplasm of the cells is only weekly stained by the dye. Note the rupture of the epithelial barrier in (B), whereas the barrier integrity in QiOne $\AA 2$ Pro protected cells in (C) is nearly similar to the untreated controls in (A). 


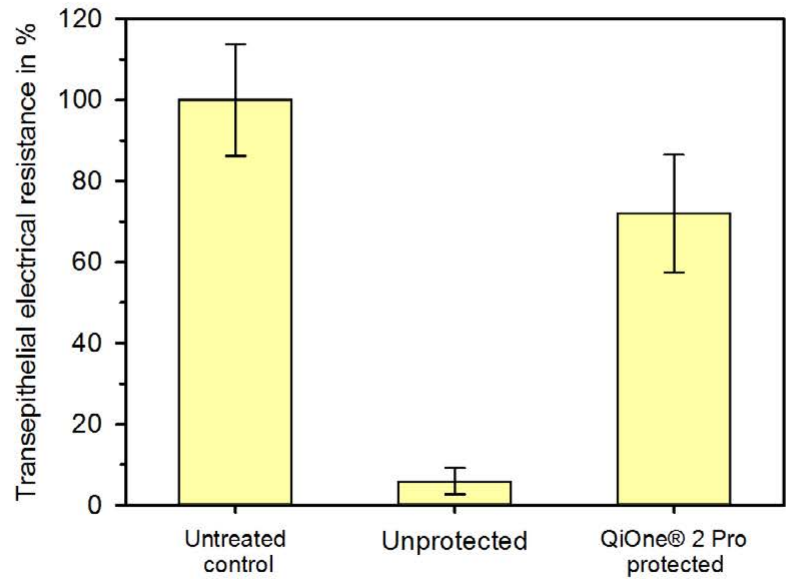

Figure 5: Presentation of the results on transepithelial electrical resistance (TEER) after mobile phone exposure with and without QiOne $\AA 2$ Pro for 4 hours and subsequent cultivation for 8 hours. Note that the TEER of untreated control and QiOne ${ }^{\circledR} 2$ Pro protected cells do not differ from each other, whereas unprotected cells have a significant decreased TEER due to a rupture of the epithelial barrier. Data represent mean value \pm standard deviation of three independent experiments.

loss of barrier integrity. The TEER value for the QiOne ${ }^{\circledR} 2$ Pro protected cells was $1,837 \pm 349 \Omega / \mathrm{cm}^{2}$ and for the untreated controls $2,542 \pm 389 \Omega / \mathrm{cm}^{2}$ (all mean value \pm standard deviation). The difference between protected and untreated cells was statistically not significant, whereas the difference to the unprotected cells was highly significant ( $\mathrm{p} \leq 0,01$; twotailed Wilcoxon-Mann-Whitney test; $n=3$ ). When calculating the relative values by setting the TEER of the untreated controls as $100 \pm 13.8 \%$, the QiOne ${ }^{\circledR} 2$ Pro protected cells had an value of $72.6 \pm 14.5 \%$ and the unprotected cells of $6.0 \pm$ $3.2 \%$ (all mean values \pm standard deviations; Figure 5). Again, the data demonstrate the effectiveness of the device against mobile phone radiation.

\section{DISCUSSION}

Bhattacharyya et al. [15] have summarized in their review that reactive oxygen species are generated as by-products of normal cellular metabolic activities which can be inactivated by endogenous enzymes such as superoxide dismutase, glutathione peroxidase and catalase. However, reactive oxygen species are generated as a response by a number of traumatic influences acting on our body. Among these are ultraviolet radiation, cigarette smoking, alcohol, nonsteroidal anti-inflammatory drugs, ischemia-reperfusion injury, chronic infections and inflammatory disorders.
Moreover, mobile phone radiation is also known to produce an excess of reactive oxygen radicals [10-13,16-20] which cannot be inactivated by the enzymes mentioned above. Since the epithelial cells of the intestinal barrier have a high turnover rate, they are more sensitive against oxidative stress which can induce oxidative injury and inflammatory responses involving a deficiency of the epithelium and immune/inflammation mediating cells [15].

Prompted by this background cultured intestinal cells were used to examine the effect of oxidative stress on the regenerative potential and the integrity of the epithelial barrier. According to Vergauwen [21] "IPEC-J2 cells are intestinal porcine enterocytes isolated from the jejunum of a neonatal piglet. The IPEC-J2 cell line is unique as it is derived from the small intestine and is neither transformed nor tumorigenic in nature. IPEC-J2 cells mimic the human physiology more closely than any other cell line of non-human origin". The cells were originally isolated in 1989 by Helen Berschneider at the University of North Carolina [22]. The advantage of the IPEC-J2 cell line as an in vitro model originates from its morphological and functional similarities with intestinal epithelial cells in vivo. IPEC-J2 cells have microvilli on their apical side and tight junctions to act as a barrier and reflecting epithelial functionality [23]. The determination of TEER is a technique that provides information about the uniformity of the IPEC-J2 cell layer on the microporous filter membrane and the integrity of the tight junctions formed between the polarized cells. Therefore, TEER measurements are often used to study epithelial barrier function [1].

The present results with QiOne ${ }^{\circledR} 2$ Pro complement confirm our previous findings in which we demonstrated that this device was able to protect functional neutrophils against mobile phone radiation [24]. In these experiments, cell viability was checked by the generation of superoxide anion radicals in the course of an oxidative or respiratory burst. Mobile phone radiation in unprotected functional neutrophils caused a reduction in superoxide anion radical generation by approximately $40 \%$ in comparison to untreated cells. In contrast, QiOne ${ }^{\circledR} 2$ Pro protected cells showed a reduction in superoxide anion radical generation by only $16 \%$ in comparison to untreated cells. In the present experiments with IPEC-J2 cells the regeneration values for unprotected and QiOne ${ }^{\circledR} 2$ Pro protected cells were in the same range as in the previous experiments with functional neutrophils. However, the examination of the integrity of a three-dimensional intestinal barrier demonstrated a much higher sensitivity against oxidative stress from mobile phone radiation. This is in accordance to the findings reviewed by Bhattacharyya et al. [15]. The use of QiOne $\AA 2$ Pro protected the cells in a significant manner as shown here. 


\section{Research Article}

Although the principles of quantum electrodynamics (QED) are not really accepted in conventional medicine as a method to influence the state of water, the present investigation has shown that coherent water as generated by use of QiOne ${ }^{\circledR}$ 2 Pro obviously has a definite positive impact on cells by increasing their resistance against exogenous traumatic influences such as mobile phone radiation. It has been stated that electromagnetic fields can be coupled to coherent systems resulting in a "self-trapping" which causes a common in phase dynamical oscillation [25-28]. As a matter of fact, the coherent system might be protected against exogenous electromagnetic fields like the inner part of a Faraday cage.

\section{REFERENCES}

1. Lea T (2015) Epithelial cell models; general introduction. In: Verhoeckx K. et al. (eds) The Impact of Food Bioactives on Health. Springer, Cham, pp. 95-102.

2. Wang H, Zhai N, Chen Y, Chongyang F, Huang K (2018) OTA induces intestinal epithelial barrier dysfunction and tight junction disruption in IPEC-J2 cells through ROS/Ca2+-mediated MLCK activation. Environ Pollution 242: 106-112.

3. Funk RHW, Monsees T, Özkucur N (2009) Electromagnetic effects-from cell biology to medicine. Progr Histochem Cytochem 43: 177-264.

4. Giuliani L, Soffritti M (2010) Non-thermal effects and mechanisms of interaction between electromagnetic fields and living matter. Eur J Oncol.

5. Panagopoulos DJ, Johansson O, Carlo GL (2015) Polarization: A key difference between man-made and natural electromagnetic fields, in regard to biological activity. Scientific Reports 5: 14914.

6. Barnes F, Greenebaum B (2016) Some effects of weak magnetic fields on biological systems-RF fields can change radical concentrations and cancer cell growth rates. IEEE Power Electronics Magazine 3: 60-68.

7. Yakymenko I, Sidorik E, Henshel D, Kyrylenko S (2014) Low intensity radiofrequency radiation: A new oxidant for living cells. Oxid Antioxid Med Sci 3: 1-3.

8. Yakymenko I, Tsybulin O, Sidorik E, Henshel D, Kyrylenko O, et al. (2016) Oxidative mechanisms of biological activity of lowintensity radiofrequency radiation. Electromagn Biol Med 35: 186-202.

9. Funk RHW, Monsees TK (2006) Effects of electromagnetic fields on cells: Physiological and therapeutical approaches and molecular mechanisms of interaction. Cells Tissues Organs 182: 59-78.

10. Wang H, Zhang X (2017) Magnetic fields and reactive oxygen species. Int J Mol Sci 18: 2175-2195.

11. Hou Q, Wang M, Wu S, Ma X, An G, et al. (2015) Oxidative changes and apoptosis induced by $1800-\mathrm{MHz}$ electromagnetic radiation in NIH/3T3 cells. Electromagn Biol Med 34: 85-92.

12. Sieroń K, Knapik K, Onik G, Romuk E, Birkner E, et al. (2021) Electromagnetic fields modify redox balance in the rat gastrointestinal tract. Front Public Health 9: 710484.
13. Geens MM, Niewold TA (2011) Optimizing culture conditions of a porcine epithelial cell line IPEC-J2 through a histological and physiological characterization. Cytotechnology 63: 415-423.

14. Bernardini C, Algieri C, Mantia LD, Zannoni A, Salaroli R, et al. (2021) Relationship between serum concentration, functional parameters and cell bioenergetics in IPEC-J2 cell line. Histochem Cell Biol 156: 59-67.

15. Bhattacharyya A, Chattopadhyay R, Mitra S, Crowe SE (2014) Oxidative stress: An essential factor in the pathogenesis of gastrointestinal mucosal diseases. Physiol Rev 94: 329-354.

16. Balci M, Devrim E, Durak I (2007) Effects of mobile phones on oxidant/antioxidant balance in cornea and lens of rats. Curr Eye Res 32: 21-25.

17. Meral I, Mert H, Mert N, Deger Y, Yoruk I, et al. (2007) Effects of $900-\mathrm{MHz}$ electromagnetic field emitted from cellular phone on brain oxidative stress and some vitamin levels of guinea pigs. Brain Res 1169: 120-124.

18. Oktem F, Ozguner F, Mollaoglu H, Koyu A, Uz E (2005) Oxidative damage in the kidney induced by $900-\mathrm{MHz}-\mathrm{emitted}$ mobile phone: protection by melatonin. Arch Med Res 36: 350-355.

19. Oral B, Guney M, Ozguner F, Karahan N, Mungan T, et al. (2006) Endometrial apoptosis induced by a $900-\mathrm{MHz}$ mobile phone: Preventive effects of vitamins E and C. Adv Ther 23: 957-973.

20. Ozguner F, Bardak Y, Comlekci S (2006) Protective effects of melatonin and caffeic acid phenethyl ester against retinal oxidative stress in long-term use of mobile phone: A comparative study. Mol Cell Biochem 282: 83-88.

21. Vergauwen H, Verhoeckx K, Lopez-Exposito I, Kleiveland C, Lea T, et al. (2015) The IPEC-J2 cell line. In: (eds) The Impact of Food Bioactives on Health. Springer, Cham, pp. 125-134.

22. Berschneider HM (1989) Development of normal cultured small intestinal epithelial cell lines which transport $\mathrm{Na}$ and $\mathrm{Cl}$. Gastroenterology 96: A41.

23. Schierack P, Nordhoff M, Pollmann M, Weyrauch KD, Amasheh S, et al. (2006) Characterization of a porcine intestinal epithelial cell line for in vitro studies of microbial pathogenesis in swine. Histochem Cell Biol 125: 293-305.

24. Dartsch PC (2021) QiOne ${ }^{\circledR} 2$ Pro-investigations on its potential for the exclusion of unwanted cellular effects of mobile phone radiation. Jpn J Med 4: 484-488.

25. Bono I, Del Giudice E, Gamberale L, Henry M (2012) Emergence of the coherent structure of liquid water. Water 4: 510-532.

26. Preparata G (1995) QED, Coherence in Matter. World Scientific, Singapore-London-New Jersey.

27. Arani R, Bono I, Del Giudice E, Preparata G (1995) QED coherence and the thermodynamics of water. Int J Mod Phys B 9: 1813-1841.

28. Blasone M, Jizba M, Vitiello G (2011) Quantum Field Theory and ist Macroscopic Manifestations. Imperial College Press.

Citation: Dartsch PC (2021) Protective Effect of QiOne ${ }^{\circledR} 2$ Pro on Cultured Intestinal Epithelial Cells after Mobile Phone Radiation. Appl Cell Biol, 9(3), 2021 [69-74] 